\title{
Pensando sobre formação docente, subjetividade e experiência de si a partir da escrita de estudantes de Pedagogia
}

Roney Polato de Castro*

DOI: $10.1590 / 0103-7307201607903$

\section{Resumo}

$\mathrm{O}$ artigo discute as experiências de estudantes de um curso de Pedagogia em uma disciplina que trabalha com as temáticas das relações de gênero e sexualidades. 0 foco de análise são as produções das estudantes em textos denominados "diários de bordo", que contêm narrativas escritas a partir das experiências

* Universidade Federal de Juiz de Fora - Faculdade de Educação, Programa de PósGraduação em Educação, Juiz de Fora, MG, Brasil. polatojf@yahoo.com.br vividas e do que foi pensado sobre as temáticas abordadas nas aulas. As análises dessas escritas tornaram visíveis as questões que as estudantes levantam sobre o exercício da docência, seus deslocamentos analíticos acerca de suas próprias subjetividades, os processos inventivos de produção de si e os estranhamentos sobre o saber de si e dos outros, além da própria escrita como atividade capaz de produzir outros modos de narrar-se a si mesmas.

Palavras-chave: diário de bordo, escrita, formação docente, experiência, sexualidades 


\title{
Thinking about docent training, and subjectivity experience of oneself from the writing of pedagogy students
}

\begin{abstract}
This article discusses the experiences of Pedagogy students in a course on gender relations and sexuality. The analytical focus is the production of students in journals that contain written narratives on their lived experiences and on what was taught in class. The analysis of the students' writings allowed us to identify their questions on the teaching, their analytical displacement regarding their own subjectivities, the inventive production of themselves, the estrangement about the knowledge of themselves and of others, as well as the actual writing as activity capable of producing other ways of narrating to themselves.
\end{abstract}

Keywords: logbook, writing, docent training, experience, sexualities 
Uma disciplina acadêmica, em um curso de Pedagogia de uma universidade pública. Sua discussão: as relações de gênero, as sexualidades e a educação. Uma tarefa: produzir, ao longo do curso, um diário de bordo. 0 sentido dado à tarefa se aproxima da ideia de uma viagem. Um documento que registra narrativas, pensamentos, sentimentos que dizem de um processo de constituição subjetiva. A ideia da viagem está relacionada ao movimento por/entre diferentes ideias, aos deslocamentos por/entre crenças e valores, aos caminhos percorridos pelos textos, às imagens, às narrativas e às memórias, à produção de experiências de pensamento e de vida. 0 diário de bordo tem como objetivo registrar esse percurso pela disciplina: que experiências são produzidas por estudantes ${ }^{1}$ de Pedagogia em uma disciplina que trata das relações de gênero, sexualidades e educação? Como essas experiências se materializam na escrita das estudantes em seus diários de bordo?

Entendendo que uma disciplina acadêmica dispõe de estratégias de produção de experiências e de constituição de subjetividades, aposto ${ }^{2}$ na problematização dessa escrita no diário de bordo. As estudantes são orientadas a registrar os movimentos de pensar, sentir e agir a partir das discussões realizadas ao longo do semestre, focando nas relações entre gênero, sexualidade e educação. A partir desses diários, discuto a experiência constitutiva de sujeitos e, portanto, formativa, possibilitada por uma disciplina que discute as relações entre gênero e sexualidade e a educação, entendendo-as como categorias formadoras de sujeitos generificados e sexualizados por meio de discursos e práticas históricos, sociais e culturais. Com Michel Foucault e Jorge Larrosa, tomo a noção de experiência como um modo de subjetivação e de dessubjetivação, ou seja, de constituição subjetiva, mas também de desprendimento do sujeito de si mesmo (Foucault, 2009). Aposto na ideia de que as aulas e as atividades da disciplina podem funcionar como mecanismos de produções de experiências de si - conceito abordado adiante -, e os diários de bordo constituem-se como espaços de escrita a partir dessa experiência, registrando deslocamentos, rupturas e suspeitas das estudantes para consigo mesmas, suas ideias, seus comportamentos e valores.

Com essas análises, busco atravessar ${ }^{3}$ a ideia de formação docente com experiência, pensando

1. As turmas são constituídas, em sua grande maioria, por estudantes autoidentificadas como pertencentes ao gênero feminino. Por isso, opto por utilizar em todo o artigo a referência ao feminino (a(as) estudantes).

2. Assumo a escrita na primeira pessoa, na perspectiva de uma pesquisa e de uma escrita produzidas com a experiência que é subjetiva, particular e que diz do sujeito que as produz.

3. 0 dicionário on line Caldas Aulete me auxilia a pensar no sentido que desejo conferir ao "atravessamento": passar, passar entre, passar por, pelo meio, passar um pelo outro cruzando-se, penetrar, perfurar. Assim, formação docente, educação, relações de gênero, sexualidades passam umas pelas outras, pelo meio, cruzam-se, penetram-se, afetam-se. Significado retirado em 14 de abril de 2014, de:

<http://www.aulete.com.br/atravessar>. 
que nesse processo se constituem sujeitosdocentes, assim como pode ser possível transformá-los, promovendo outros modos de ser docente. Nesse sentido, as análises deste texto se apoiam em uma noção de subjetividade inspirada nos estudos de Michel Foucault, que a apresenta não como uma substância ou uma determinação transcendental, mas como "uma reflexividade que se poderia chamar de prática: uma maneira de se relacionar consigo mesmo para se construir, para se elaborar" (Gros, 2008, p. 128). Ao dirigir a atenção para as práticas que pretendem formar docentes, é possível pensar nos modos como sujeitos se produzem a partir delas e, assim, constituem subjetividades. Compreendo essas práticas como dispositivos que marcam rupturas, inaugurando outras preocupações para a formação docente, sobretudo, a preocupação de implicar politicamente essa formação.

Partindo desta breve introdução, o artigo se organiza em duas partes complementares. Primeiro, dirige-se a pensar mais diretamente a disciplina e a proposta de escrita que fundamenta a pesquisa realizada e suas análises. Prosseguindo, passo a algumas problematizações de excertos narrativos retirados dos diários de bordo construídos pelas estudantes, considerando algumas possibilidades de acompanhar a produção subjetiva de si das estudantes e as transformações nos modos de pensar, agir, sentir, materializados na escrita dos diários.

\section{Uma disciplina acadêmica e sua proposta de escrita: direcionamentos}

A escrita de si das estudantes de Pedagogia, que institui certas relações delas consigo mesmas, narra a produção de experiências com a disciplina. Por meio dessa escrita, das narrativas de si, tais processos se materializam, se tornam visíveis, possibilitando acompanhar movimentos de constituição das subjetividades docentes. E, como esse processo se vincula a uma disciplina acadêmica, que discute temáticas em particular, é possível acompanhar narrativas que contam sobre valores, concepções, crenças, enfim, aprendizagens em torno das relações de gênero e sexualidades. Nesse sentido, as narrativas apontam para os modos como somos afetados pelas "pedagogias da sexualidade" (Louro, 2001), ou seja, os modos como nos constituímos pelos discursos presentes nos rituais, nos artefatos culturais, nas relações sociais, nas instituições, em torno das sexualidades e dos modos de constituir sujeitos femininos e masculinos. "As muitas formas de fazer-se mulher ou homem, as várias possibilidades de viver prazeres e desejos corporais são sempre sugeridas, anunciadas, promovidas socialmente” (p. 09). 
Delineando as perspectivas que apoiam o objetivo de problematizar a produção de subjetividades na experiência de escrita dos diários de bordo, as categorias "relações de gênero", "sexualidades”, “educação", "formação docente”, "docência” são pensadas como construções sociais, culturais e históricas que atravessam as experiências e constituem os sujeitos. Tais problematizações se vinculam aos estudos foucaultianos e aos estudos pós-estruturalistas de gênero, sexualidade e educação. Desse modo, assumo que sujeitos são constituídos por práticas discursivas e não discursivas, processo colocado em funcionamento num determinado contexto cultural e histórico. Nessa perspectiva, a linguagem é constitutiva dos sujeitos, ou seja, muito mais do que apenas descrever ou representar a realidade, o que as estudantes trazem à tona nas aulas e nos “diários de bordo" tem um caráter performativo e produtivo (Silva, 2006), ou seja, suas narrativas remetem a sistemas de significação que, por sua vez, sustentam e são sustentados por regimes de verdade (Foucault, 2006). Assim, os estudos pós-estruturalistas podem servir como ferramentas para problematizar e explorar a indeterminação, a ambiguidade, a instabilidade, a multiplicidade e a provisoriedade dos sentidos que são produzidos pelas estudantes no encontro com as discussões sobre corpos, gêneros e sexualidades (Meyer \& Soares, 2005).

Ao trazer para este texto a discussão sobre uma disciplina acadêmica na qual estudantes de Pedagogia se envolvem no debate acerca de categorias que são pouco visibilizadas nos currículos universitários de formação docente (Silva, 2011), ressalto as condições singulares de seu funcionamento e seus efeitos na formação das estudantes, entendendo, como foi dito anteriormente, que a formação docente vai além da preparação técnica para a docência: formação como produção de sujeitos.

A formação inicial e continuada de professoras(es) se insere no conjunto de dispositivos vinculados a contextos sociais, culturais e históricos, que colocam em ação certas estratégias e técnicas nas quais o mais importante a analisar pode não ser o fato de que ensinem algo "exterior", um "corpo de conhecimentos", e, sim, os modos como por meio delas os sujeitos em formação - no caso, as estudantes de Pedagogia de uma universidade pública - produzem ou transformam a experiência que têm de si mesmos, os modos como se tornam objetos para si mesmos, e mais, como suas experiências de gênero e sexualidade e como suas imagens corporais são elaboradas e reelaboradas a partir de suas relações consigo próprios. Larrosa (2002) define esse processo como 
o resultado de um complexo processo histórico de fabricação no qual se entrecruzam os discursos que definem a verdade do sujeito, as práticas que regulam seu comportamento e as formas de subjetividade nas quais se constitui sua própria interioridade. É a própria experiência de si que se constitui historicamente como aquilo que pode e deve ser pensado. A experiência de si, historicamente constituída, é aquilo a respeito do qual o sujeito se oferece seu próprio ser quando se observa, se decifra, se interpreta, se descreve, se julga, se narra, se domina, quando faz determinadas coisas consigo mesmo, etc. (p. 43)

Desse modo, as práticas educativas de formação não seriam apenas mediadoras do desenvolvimento dos indivíduos. As pedagogias são práticas que têm papel produtivo na fabricação ativa dos sujeitos (Larrosa, 2002).

A disciplina que se constitui objeto de análise foi criada no ano de 2009 e vem sendo oferecida, desde então, como optativa, para o curso de Pedagogia, com carga horária de 60 horas ( 4 créditos). As aulas se organizam em torno da discussão embasada por textos de periódicos e livros, aulas expositivas dialogadas, discussões em grupos, uso de vídeos e filmes, entre outras estratégias.

Dentre as estratégias utilizadas está o diário de bordo. A cada semestre é solicitado às estudantes, no primeiro dia de aulas, que produzam, ao longo de todo o período letivo, um diário e o entreguem ao final do semestre. Nele devem ser registrados os movimentos de análise empreendidos a partir das aulas da disciplina, relacionando-as a fatos ocorridos no cotidiano (convivência familiar, acadêmica, social; estágios e prática profissional) e aos artefatos culturais (programas de TV, matérias de jornais e revistas, músicas, filmes, entre outros) com os quais as estudantes têm contato e que poderiam suscitar conexões com os textos e as discussões das aulas. 0 objetivo principal é o de produzir registros que acompanhem os processos subjetivos de formação a partir das reflexões que a disciplina provoca durante as aulas e para além delas.

Transcorridos mais de dois anos em que a disciplina vem sendo oferecida semestralmente para o curso de Pedagogia, tenho notado que, em se tratando dos temas relacionados aos gêneros e às sexualidades, a participação nas discussões pode ser difícil para algumas estudantes. Manifestar suas concepções, suas crenças e seus valores pessoais e participar de debates envolvendo a problematização dessas crenças e valores, é um processo que pode deixar algumas delas desconfortáveis, limitando 
sua participação nas aulas. É possível perceber isso, seja pelos silêncios, pelos burburinhos e conversas paralelas, seja pelas próprias manifestações das estudantes, que dizem desse desconforto. Assim, o diário de bordo foi pensado também como uma das estratégias para que elas pudessem se manifestar com maior liberdade e para que, como docente e pesquisador, eu pudesse conhecer as questões que as instigaram.

As estratégias dessa disciplina podem ser consideradas dispositivos com os quais as estudantes produzem experiências capazes de "desprendê-las de si mesmas", como propõe Foucault (2009). Em se tratando da formação docente, essa ideia pode ser produtiva, na medida em que, ao envolver-se na problematização de valores e concepções naturalizadas, as estudantes podem “dar um passo atrás”, amparadas pelo grupo, pelo professor e pelas estratégias utilizadas nas aulas. Isso não significa "desenterrar um conhecimento subjacente ou um conjunto de práticas subjacente, uma episteme, que permite às declarações serem consideradas verdadeiras ou falsas" (Marshall, 2008, p. 31), mas “é o que permite a alguém dar um passo para trás em relação a essa maneira de agir e reagir, a apresentá-la como um objeto de pensamento e questioná-la em relação a seu significado, suas condições e suas metas” (p. 30).

Pode ser relevante também destacar que a elaboração dos diários de bordo se constitui em um investimento para que narrem a si mesmas, para que registrem seus pensamentos - enfim, uma estratégia que se situa nas fronteiras entre os rituais acadêmicos (a exigência de trabalhos utilizados como instrumentos de avaliação) e as atividades cotidianas das estudantes. As narrativas orais e escritas podem ser consideradas como dispositivos por meios dos quais os sujeitos se colocam em processo de experimentação de si. As narrativas nos diários de bordo podem ser pensadas como um tipo de prática ou de exercício de "escrita de si” (Foucault, 2006). Uma escrita que funciona como "invenção de si”, na medida em que possibilita construir e reconstruir acontecimentos, ideias, memórias, imagens e representações, um dispositivo que produz processos de subjetivação, ao mesmo tempo em que movimenta as subjetividades das estudantes, possibilitando novos modos de existência.

\section{As experiências narradas nos diários de bordo e a produção subjetiva de si}

Apostando na ideia de que as narrativas escritas pelas estudantes a partir dos processos de formação docente se constituem como dispositivos que instauram rela- 
ções subjetivas e produzem modos de estar no mundo e de experienciar a docência, problematizo alguns excertos narrativos 4 transcritos dos diários de bordo. Um primeiro movimento dessas escritas diz das impressões sobre a disciplina:

“Depois do período tendo aulas sobre Gênero e Sexualidade é possível perceber que muita coisa deixou de parecer tão natural e aceitável. Ouvir depoimentos de colegas sobre situações vivenciadas nas suas turmas de estágio, assim como declarações pessoais foram muito importantes para que compreendesse a complexidade do tema." (Luana) ${ }^{5}$

"Acredito que a disciplina foi muito além da minha formação profissional, perpassando até mesmo questões pessoais, algumas vezes dolorosas. As aulas me fizeram ultrapassar os limites da sala de aula, despertando meu interesse sobre os temas expostos. Muitas vezes tive que tentar desconstruir até mesmo algumas concepções enraizadas, processo de desconstrução que não ocorreu de maneira fácil; derrubar valores construídos durante vários anos em nossas vidas é uma tarefa bem dificil e conflituosa, mas acredito que seja necessário." (Maria)

A disciplina se apresenta como um dispositivo formativo capaz de promover importantes problematizações sobre a docência. Ao abordar as relações entre gênero, sexualidade e educação, pode provocar movimentos, abalos, deslocamentos, suspeitas para com as formas naturalizadas de pensar e agir no cotidiano e nas práticas pedagógicas escolares. Nos excertos anteriormente apresentados, Luana nos diz que, após participar das aulas, "muita coisa deixou de parecer tão natural e aceitável". Maria relata que participar da disciplina se configurou como um processo “que não ocorreu de maneira fácil”, manifestando seus sentimentos em relação às mudanças no olhar sobre si mesma e identificando as aulas como mecanismos que lhe permitiram "desconstruir até mesmo algumas concepções enraizadas" e "derrubar valores construídos". Ao concluírem os diários, foi solicitado às estudantes que narrassem as experiências produzidas ao terem cursado a disciplina. Tais produções manifestam um duplo movimento de subjetivação, colocado em funcionamento pe-

4. Os excertos dos diários de bordo estarão transcritos neste texto em itálico e espaçamento simples, colocados com recuo de $2 \mathrm{~cm}$ à direita e à esquerda, entre aspas, com o objetivo de diferenciá-los das demais citações.

5. Os nomes das estudantes foram substituídos por pseudônimos, a fim de garantir 0 anonimato. las aulas e também pelo ritual de escrita do diário. Desse modo, as aulas e tudo o que foi produzido a partir dela - incluindo os diários de bordo - são tecnologias que produzem uma experiência de si, “que permitem aos indivíduos efetuar, por conta 
própria ou com a ajuda de outros, certo número de operações sobre seu corpo e sua alma, pensamentos, conduta..., obtendo assim uma transformação de si mesmos" (Foucault, 1990, p. 48). A narrativa de Luana ressalta que os depoimentos de colegas sobre situações vividas nos estágios e as histórias pessoais relatadas foram elementos que provocaram outras formas de pensar. Remeto-me à presença das narrativas e ressalto sua relevância na construção das discussões durante as aulas e na elaboração das escritas das estudantes nos diários. Ao relatar acontecimentos ocorridos nos estágios, por exemplo, iniciava-se nas aulas um jogo de ideias cujo objetivo não era o convencimento ou a certeza de que a turma construiria um pensamento unânime. $\mathrm{E}$ essas situações apareceram nos relatos escritos dos diários.

"Diário, vou te contar uma situação que me deixou bastante intrigada nesta semana. Estava em uma escola de educação infantil e indo para a sala dos professores me deparei com a seguinte cena: um grupo de professoras fazendo comentários depreciativos em relação a um aluno que elas diziam ser 'viadinho'. As 'docentes' - entre aspas porque não sei se realmente elas merecem esta denominação - falavam entre gargalhadas que o menino ficava igual a uma bichinha na fila de entrada e que quando crescesse não escaparia de ser gay. Fiquei até com vergonha de ouvir as palavras delas em relação ao aluno". (Roberta)

As estudantes fizeram das aulas espaços de narração das experiências construídas nos estágios, associando-as às problematizações que empreendíamos sobre as relações de gênero e as sexualidades nos ambientes escolares. Situações como a que Roberta relata em seu diário e que ganhou contornos de debate, na medida em que as demais estudantes relacionavam tais fatos às suas próprias experiências, construindo certas representações da docência. Roberta narra essa construção quando coloca em dúvida um sentido da palavra “docentes”, questionando se as professoras deveriam ser denominadas desse modo, devido à postura que tiveram. Viver essa experiência e discuti-la no diário de bordo e na sala de aula parece movimentar as representações de Roberta em relação à docência (e eu arriscaria a dizer que o mesmo acontece com as demais estudantes). Esse processo fez com que Roberta se colocasse no lugar das professoras, identificando no comportamento delas uma espécie de "falha". Sem a pretensão de cair na armadilha do julgamento moral e situando as atitudes das professoras num contexto social, cultural e histórico que lhes possibilita 
dizer e agir da forma como Roberta observou, entendo que a estudante identifica uma atitude inadequada e parece distanciar-se dela.

Outra narrativa pode ser relevante para pensar a presença das experiências dos estágios no processo subjetivo de constituição da docência pelas estudantes:

"Em um recreio do $1^{\circ}$ ano no colégio, quando brincava com os alunos do $1 B$ e do $1 D$ porque o recreio deles é junto - aconteceu uma situação inusitada. Uma aluna do $1 B$ levou um estojo de maquiagem e pediu para eu maquiar as meninas. Formou-se uma enorme fila de meninas das duas salas. Enquanto isso acontecia aproximou-se um menino e olhava aquilo tudo. Aí eu intervi': - Você quer maquiar também? - Eu quero tia! - Então entra na fila e espera sua vez! Ele aguardava sua vez ansiosamente, quando finalmente chegou eu escolhi uma cor de sombra mais discreta (branca) e passei no olho dele. As meninas olharam e ficaram zombando dele, nessa hora eu intervi: - Só porque ele é menino não pode maquiar? Qual o problema? Ele é criança igual a vocês! E nessa explicação as meninas se conformaram e não falaram mais nada. 0 menino ficou contente e sair para brincar com outras crianças.... Essa situação foi tão inusitada que trouxe para nossa sala de aula e discutimos muito. Várias foram as questões trazidas e me ficou uma pergunta: maquiar meninos, pode ou não pode? Eis a questão!!!". (Pâmela)

A partir da narrativa de Roberta e de Pâmela, saliento que o processo de constituição das subjetividades docentes é algo conflituoso e inacabado, estendendo-se para toda a vida, e dele fazem parte e destacam-se as experiências nos estágios. Ao discutir relações de gênero e sexualidades, temas que, aparentemente, não são abordados nas disciplinas de estágio, as estudantes são provocadas a pensar as práticas pedagógicas escolares de outros modos, modificar suas lentes, para que possam enxergar os discursos e as práticas em funcionamento nas escolas como produto e produtoras de sujeitos de gênero e sexualidade. Ao observar a atitude das professoras que classificam o aluno como "viadinho" e "bichinha", Roberta o faz a partir das discussões realizadas nas aulas. 0 mesmo posso dizer em relação às experiências de Pâmela, que se envolve numa situação na qual ela mesma lança mão das ferramentas discutidas durante as aulas e se questiona: "meninos devem usar maquiagem"? Na

6. Considero relevante destacar que a escrita das estudantes foi mantida exatamente como estava nos diários de bordo. medida em que os fatos vivenciados nos estágios provocam o pensamento sobre a docência, eles se 
tornam objeto de análise nas aulas e no diário de bordo. Pâmela construiu uma saída possível para a situação vivenciada, dizendo que o menino era criança como as meninas, embora seja possível problematizar que a alternativa encontrada mantém a lógica binária do gênero. Ao fazer isso, a estudante associou a maquiagem a uma brincadeira infantil, retirando dela a marcação de gênero e, portanto, excluindo a possibilidade de discutir com as crianças esse aspecto.

As narrativas aqui transcritas e outras que foram lidas nos diários possibilitam argumentar, nesse caso, que as experiências dos estágios, das aulas de nossa disciplina e, mesmo, a experiência de escrita do diário são capazes de desprender as estudantes de si mesmas. Nesse sentido, a experiência é algo que possibilita "desgarrar al sujeto de símismo, de manera que no sea ya el sujeto como tal, que sea completamente otro de símismo, de modo de llegar a su aniquilación, su disociación" (Foucault, 2009, p. 12). Tal ideia se aproxima do que pensa Larrosa (2014), para quem a experiência é um encontro ou uma relação com algo que se experimenta, que se prova. Retomando a narrativa de Luana, saliento que a dimensão formativa da experiência não está no acúmulo de vivências num processo linear, mas é evidente sua incompletude e instabilidade:

“Seria ilusão achar que agora sabemos lidar com as mais diversas situações que aparecerão no nosso cotidiano, antes de tudo como sujeito social, imerso nas relações sociais e por consequência no ambiente escolar. Fato é que nesta última circunstância nos cabe uma intervenção maior e mais bem planejada já que toda a atividade escolar deve ser realizada de forma intencional, à medida que nossa omissão significa o reforço de uma prática hegemônica." (Luana)

Os argumentos de Luana se coadunam com os de Pâmela, que analisa a situação de ter maquiado um menino na hora do recreio durante o estágio num colégio. As estudantes fazem do diário um espaço para perguntas que geram outras perguntas, um movimento que lhes permite pensar de outros modos as situações já vivenciadas a partir dos debates nas aulas. A narrativa de Pâmela destaca a discussão do fato por ela apresentado à turma, momento no qual as suas colegas também se manifestaram sobre a questão que a instigava: "maquiar meninos, pode ou não pode? Eis a questão!!!”. Colocam-se em jogo os discursos e as práticas constitutivos das relações de gênero, os quais delimitam fronteiras a partir dos símbolos, dos objetos, dos gestos, 
das falas de cada sujeito. Para Pâmela e para as colegas de sua turma, passar ou não maquiagem num menino tornou-se uma questão importante, por meio da qual elas colocaram em xeque suas concepções de masculinidade e feminilidade. A própria Pâmela, ao agir maquiando o menino e dizendo às meninas que ele também podia se maquiar, pois, afinal, também era criança como elas, inaugura possibilidades de discutir modos outros de pensar as relações de gênero na escola, e isso se torna uma questão a ser narrada e escrita, uma experiência que coloca o sujeito à prova, quando em relação com algo que se experimenta (Larrosa, 2014). É também Pâmela que se manifesta sobre o processo de escrita no diário:

“Gosto muito neste espaço de discutir os textos da disciplina. É um momento que posso dialogar comigo mesma e expor minha opinião sem medo dos outros, posso falar o tanto que eu quero (muito ou pouco - depende da inspiração) e ainda dizer algo que não disse na aula pelo tempo ou porque ainda não tinha feito tal reflexão...". (Pâmela)

Os escritos do diário de bordo parecem dar visibilidade a um processo inventivo: as estudantes dobrando-se sobre si mesmas, apropriando-se de um fluxo de ideias, valores, imagens que irrompem de seus "eus", que provocam novos posicionamentos sobre/com gêneros e sexualidades e sobre a docência. Uma delas, ao manifestarse sobre as aulas da disciplina, diz desse movimento:

"Está sendo ótimo escrever o diário, pois é através dele que reflito e me coloco sobre as questões. Acredito no poder do travesseiro, que me permite uma reflexão mais tranquila e consistente. Discutimos o conceito gay, que é alguém que gosta de outro alguém do mesmo sexo. Muitas pessoas acham que o gay é apenas o homem que se veste de mulher e repassam isso a seus filhos, alunos. Uma pergunta que o professor lançou para discussão em sala, me chamou atenção: nascemos homens e mulheres ou aprendermos a ser? No começo pensei que sim, nascemos homens e mulheres biologicamente é assim que se define. Mas, quem define? Fiquei confusa e pensei que se a sociedade definisse que sou homem, eu acreditaria que sou. Essa disciplina tem quebrado muitos paradigmas e me deixado confusa em relação ao que acreditar. Isso é bom, não é?". (Helena)

Apropriando-me da ideia do diário de bordo como um conjunto de registros de viagens, penso o processo inventivo da formação docente no qual estão envolvidas as estudantes como um constante fazer-se, como um projeto nunca terminado, mas, 
ao contrário, sempre levando a caminhos inesperados, a lugares desconhecidos, a experiências significativas (prazerosas ou não). 0 "poder do travesseiro", que Helena anuncia em sua narrativa, tem a ver com a processualidade dessa formação. 0 que ela registra em seu diário, sobre seus movimentos de reflexão, sobre o que the chama a atenção, sobre a questão que a fez pensar é parte desse processo. 0 modo como termina seu registro, dizendo que a disciplina quebrou paradigmas e a deixou "confusa”, faz pensar que esse movimento pode ser, mesmo, o de uma invenção de si. Além disso, fala do "pensar" e em mudanças nesse "pensar" sobre as identidades de gênero, colocando-se questões. Destaca-se, novamente, a ideia foucaultiana de pensamento como "o que permite a alguém dar um passo para trás", apresentandose questões e transformando-as em “objeto de pensamento" (Marshall, 2008, p. 30). Como argumenta Marshall (2008), dar um passo para trás “é o movimento pelo qual alguém se separa do que faz, de forma a estabelecê-lo como um objeto de pensamento e a refletir sobre ele como um problema .... É tratar o objeto de pensamento como um problema" (p. 31). Helena narra esse movimento provocado pela escrita no "diário de bordo": "é através dele que reflito e me coloco sobre as questões". Nesse movimento, as questões de gênero e sexualidade tornam-se "objeto de pensamento", vinculando-se ao processo de construção de significados, pela estudante, sobre essas questões. Assim, o pensamento vai além de "raciocinar”, “calcular”, "argumentar", mas serve para dar sentido ao que somos e ao que nos acontece (Larrosa, 2014).

O excerto que transcrevi do diário de Helena aponta uma das questões debatidas nas aulas: "Nascemos homens e mulheres ou aprendemos a ser?". Um movimento inspirado na célebre frase da feminista Simone de Beauvoir (1967): "Ninguém nasce mulher: torna-se mulher" (p. 9). Essas e outras questões desafiam as concepções previamente construídas das estudantes, desafiam-nas a pensar que os modos como nos constituímos mulheres e homens são parte de um investimento social, cultural e histórico para que nos tornemos o que somos. Helena também se refere à discussão sobre a homossexualidade, especialmente inspirada nos estudos foucaultianos, associando-a à discussão das identidades de gênero, em função da "confusão" com as sexualidades, ou seja, nas relações sociais o sujeito homossexual é tido como pertencendo ao gênero contrário do seu sexo biológico, fato que chama a atenção da estudante, pois ela também se coadunava com essa concepção.

“Isso é bom, não é?”. Uma questão que Helena faz ao mesmo tempo a si mesma e ao professor, estabelecendo diálogos por meio do diário de bordo, propiciando 
que as estudantes se coloquem como "estrangeiras" em um terreno aparentemente conhecido - as aulas de uma disciplina no curso de Pedagogia -, olhando-o com outros olhos, a partir de outras posições, constituindo experiências com o novo, com o inesperado. E nesse movimento provocam deslocamentos em si mesmas. Nesse caso estou pensando na experiência, assim como Larrosa (2014), como algo que nos passa, nos toca, nos acontece. A estudante Maria registra esse processo em seu diário, a partir das discussões que provocaram seu pensamento:

"Na aula que foi proposta uma atividade baseada no texto 'Marcas do corpo, marcas de poder', o meu grupo ficou com a imagem de um homem musculoso e 'desejado' pelo público masculino. No nosso grupo houve muita discussão sobre a questão dos estereótipos, sobre padrões, sobre sacrificios que as pessoas fazem para ter aquele 'corpo perfeito e desejável'. Em meio a tantas críticas que nosso grupo foi tecendo percebi de uma maneira nítida que eu estava me autocriticando, nós falávamos de pessoas que deixavam de comer, que faziam dietas malucas e que frequentavam academias de maneira exacerbada. Quando percebi estava me descrevendo, estava criticando algo que faço constantemente. Tentando seguir padrões me expunha a sacrificios, como ficar sem comer e malhar para tentar atingir o 'corpo perfeito'. Sai da aula refletindo sobre aquilo, eu que tanto critiquei a questão de se 'alienar', seguir o que a mídia propõe, tentar atingir um padrão, me vi naquela situação, fazendo exatamente tudo o que eu criticava." (Maria)

O olhar estrangeiro é, então, aquele que permite exercitar o estranhamento, a perplexidade e a descoberta diante do próprio saber-fazer, um estranhamento diante do que se julga familiar e conhecido (Meyer \& Soares, 2005). Maria apresenta esse movimento de olhar, ao constatar que a aula fez com que pensasse a si mesma, que criticasse algo que ela costuma fazer. Desse modo, os registros das viagens pela disciplina são também um registro de si, pois o diário pode provocar o movimento de olhar para si mesma, trazendo questões como: o que penso a partir das experiências vividas com a disciplina? Que concepções tenho sobre as questões discutidas? Que concepções produzi a partir delas? Assim, as estudantes colocam-se nas fronteiras entre o ter estado lá - nas aulas, naquilo que lhes é familiar nos rituais acadêmicos -e o ter que estar "de fora”, "separar-se de si mesmas”, retornar a esses espaços-tempos numa outra posição, de quem dá um passo atrás e observa, analisa, pensa e registra 
suas experiências, tentando, com o artifício da palavra, “(re)compor uma 'realidade' vivida e assim trazê-la àqueles(as) que aqui ficaram” (Santos, 2005, p. 13). Maria diz que esse movimento não se limita às aulas, mas provoca o pensamento e subjetiva, ao retomar as discussões e as reflexões lá experimentadas. Ao olhar para si mesmas, as estudantes não estão pensando ou modificando um "eu interior", algo separado do "eu externo". Analisando suas atitudes e seu comportamento na relação com seu corpo, Maria mostra que os processos de subjetivação se dobram, e a dualidade interior-exterior se desfaz, algo que também podemos observar na escrita de outra colega:

"Achei genial o conceito de heteronormatividade, pois parei para pensar e notei que eu mesma tinha atitudes de caráter heteronormativo e nem sabia. Para mim sempre foi mais tranquilo ver um homossexual vestido de homem do que de mulher e isso é uma coisa implícita. Tanto é que quando vejo um cara mais sensivel ou vaidoso não olho com os mesmos olhos. Tenho um amigo metrossexual assumido e sempre brinco com ele falando que por pouco ele não escorregava para o outro lado. Quando vimos esse assunto, falei com ele e ele riu muito dizendo que ia me processar." (Kamila)

Tornando-se como objetos para si mesmas, as estudantes dizem das redes de saber e poder que sustentam os processos formativos de sujeitosdocentes. Ao fazerem os registros nos diários de bordo, elas produzem um saber sobre si, em articulação com os saberes veiculados/produzidos nas aulas e, ao mesmo tempo, produzem-se como sujeitos, como mulheres, como futuras professoras, como pessoas que experimentam prazeres e desejos. A narrativa de Kamila articula o modo como ela vivencia as relações sociais baseadas nas sexualidades às discussões das aulas, extrapolando esse espaço. Seu registro narra a experiência de incorporar ao cotidiano as discussões sobre heteronormatividade que empreendemos nas aulas da disciplina. Assim como Maria, Kamila também narra uma espécie de processo de "autoproblematização”, interrogando-se sobre suas atitudes e pensamentos. "As interrogações produzidas nesses movimentos podem nos desafiar a embarcar em viagens que podem nos levar a mundos e realidades ao mesmo tempo diferentes e próximas das nossas; pode borrar completamente aquilo que aprendemos a conhecer, pensar, dizer e viver” (Meyer \& Soares, 2005, p. 31).

Pensar os diários de bordo como dispositivos de formação implicados na produção de sujeitosdocentes por meio da escrita. Larrosa (2002) nos diz que a experiência 
de si é um processo que depende daquilo que contamos, especialmente para nós mesmos(as).

E a experiência de si está constituída, em grande parte, a partir das narrações. 0 que somos ou, melhor ainda, o sentido de quem somos, depende das histórias que contamos e das que contamos a nós mesmos. Em particular, das construções narrativas nas quais cada um de nós é, ao mesmo tempo, o autor, o narrador e o personagem principal. (p. 48)

As estudantes produzem seus diários narrando processos de formação. Ao fazerem isso, a escrita não teria como função revelar um "eu interior" que é influenciado por um "fora” (conhecimentos, técnicas, práticas pedagógicas). Ela narra a produção de subjetividades e, por conseguinte, de experiências. As estudantes constituem certo sentido do que são, dão sentido aos lugares que ocupam, na sociedade, como muIheres, estudantes de Pedagogia, professoras em formação. Colocam-se como “sujeitos de experiência”, no sentido empregado por Foucault (2009): a escrita permite a elas o "desprender-se de si mesmas".

Foucault (2009) considera seu trabalho como a construção de “livros-experiência”, processos de escrita que proporcionam a experiência da mudança e da transformação. Quando argumenta isso, ele diz pensar na experiência como um empreendimento de dessubjetivação, que faz o sujeito “desgarrar-se de si mesmo", impedindo-o de ser sempre o mesmo. Desse modo, aproprio-me da ideia da escrita produzida pelas estudantes nos diários de bordo como uma escritaexperiência, que produz experiências, ao proporcionar que elas se desgarrem de si. Produzem-se, desse modo, diáriosexperiência: ao finalizá-los, as estudantes não são mais as mesmas.

\section{A escritaexperiência como ficção: uma formação para desfamiliarizar-se de si e do mundo}

Ainda pensando com Foucault (2009), o diário de bordo não seria uma “escritaverdade", uma escrita que demonstra um processo fixo de construção de subjetividades, mas, sim, uma escritaexperiência, que, ao se fazer, pode funcionar como criadora do mundo, preenchendo o "vazio", o "fora" que se dobra em fluxo de forças que subjetiva. Um excerto, em especial, provoca a tecer tais relações: 
"Fico triste de verdade por saber como as coisas são, mas é melhor assim que viver mentiras. Essas aulas, as discussões, os textos têm mexido muito comigo! E descobri verdades não muito legais de se ver... Minha familia é machista. Todo mundo aqui em casa é, inclusive minha mãe. Ela é submissa de uma forma que eu não aceitaria ser, mas é normal para ela. Ela se conforma e diz que 'é assim mesmo'.... Como não pude perceber isso? Como fiquei cega por tanto tempo? Eu não sei, não sei mesmo o que pensar! É estranho saber que seria diferente se eu fosse homem. É dificil aceitar.... Eu só queria fazer essa disciplina para saber como falar disso com meus alunos e olha o que está acontecendo! 0 mundo está mudando, a minha forma de ler o mundo está mudando. Estou rompendo o casulo mais um pouquinho.... Minha adolescência se baseou no meu gênero. E como não tenho pênis, saí perdendo. É absurdo! Por alguns (muitos) genes, pelo amor de Deus, gente! Quando com 15 anos eu comprei um livrinho '0 que é feminismo', daquela coleção 'Primeiros Passos', li sobre uma tal de Beauvoir e larguei para lá. Foi interessante, eu li e entendi algumas coisas, mas nunca iria imaginar o que compreendo hoje." (Amanda)

Experiência como ficção e como verdade: "saber como as coisas são é melhor do que viver mentiras". Experiências sendo tecidas nas relações de forças que provocam deslocamentos, que fazem suspeitar de valores e crenças naturalizadas, que permitem problematizar, “dar um passo atrás”. Nesse fluxo de forças, a escrita no diário de bordo parece funcionar como uma "escrita transgressora" - do pensamento, dos limites. Processo que permite a Amanda questionar-se sobre sua família, passando a olhar com mais atenção o machismo presente nas relações vividas nesse contexto. Ao mergulhar no processo da escrita nos diários, as estudantes não demonstram quem "realmente" são, nem mesmo se olham "de fora", como se houvesse essa oposição interior/exterior, uma essência constitutiva ou uma consciência autônoma. O olhar é sobre o movimento constitutivo da subjetividade, problematizando-o a partir das experiências provocadas pelas aulas da disciplina e pela narrativa de si no diário.

Chama a atenção o modo como a narrativa de Amanda remete a um processo de ver coisas que parecem ser muito óbvias, mas que são discutidas como parte de um processo de naturalização das sexualidades e das relações de gênero. Ela “descobre verdades não muito legais de se ver", que passam a ser vistas a partir da aquisição de novas lentes: “Essas aulas, as discussões, os textos têm mexido muito comigo!". Ao identificar a família como machista e a mãe como submissa a essa racionalidade, 
Amanda parece enxergar a si mesma de outros modos. Materializa-se, assim, uma escritaexperiência, fazendo transbordar um processo de constituição de subjetividades por fazer-se. A escrita, nesse sentido, não funciona como um espelho, que reflete um eu pronto, fixo. Ao olhar-se nesse espelho, as estudantes não veem uma imagem acabada. Nesse caso, as narrativas funcionariam, ao mesmo tempo, como capturas momentâneas do processo de constituição da experiência de si e como mecanismo de subjetivação. Nesse sentido, Larrosa (2014) auxilia a pensar na proposta dos diários de bordo como “um gesto de interrupção” que dá condições para que a experiência aconteça e que requer

parar para pensar, parar para olhar, parar para escutar, pensar mais devagar, olhar mais devagar, e escutar mais devagar; parar para sentir, sentir mais devagar, demorar-se nos detalhes, suspender a opinião, suspender o juízo, suspender a vontade, suspender o automatismo da ação, cultivar a atenção e a delicadeza, abrir os olhos e os ouvidos, falar sobre o que nos acontece, aprender a lentidão, escutar aos outros, cultivar a arte do encontro, calar muito, ter paciência e dar-se tempo e espaço. (p. 24)

Ao trazer para a discussão as escritas das estudantes em diários de bordo, numa disciplina acadêmica do curso de Pedagogia, a ideia é fomentar o debate sobre a formação docente, pensando que ela pode estar funcionando como espaço no qual "se aprende a 'pensar' e a 'argumentar' sobre questões educativas de determinada maneira" (Larrosa, 2002, p. 50), colaborando para a construção de uma ideia de educação que está intimamente relacionada com o social, o político e o cultural. Com isso, concebo as práticas de formação docente como espaços de produção de conhecimentos, valores e práticas, constituídos e constituidores de relações de gênero e sexualidades.

Nesse sentido, a formação vai além das verdades únicas, das certezas sobre como agir ou sobre o que pensar (e o que ignorar), mas também produz muitos questionamentos. Questões para as quais não há uma resposta segura, correta, mas que estão implicadas em um exercício de desfamiliarização: nos desfamiliarizarmos de nós mesmos (Larrosa, 2002). 


\section{Referências bibliográficas}

Beauvoir, S. (1967). O segundo sexo. II - A experiencia vivida (2a ed., 500 pp.). São Paulo: Difusão Européia do Livro.

Foucault, M. (1990). Tecnologías del yo. In M. Foucault, Tecnologías del yo y otros textos afines (pp.45-94). Barcelona: Paidós Ibérica.

Foucault, M. (2006). Ditos \& Escritos V. Ética, sexualidade, política (2a ed., 325 pp., Manoel Barros da Mota, org.). Rio de Janeiro: Forense Universitária.

Foucault, M. (2009). Cómo nace um libro-experiencia. In M. Foucault, El yo minimalista e otras conversaciones (pp. 09-17). Buenos Aires: La Marca.

Gros, F. (2008). O cuidado de si em Michel Foucault. In M. Rago \& A. Veiga-Neto (Orgs.), Figuras de Foucault (pp. 127-138). Belo Horizonte: Autêntica.

Larrosa, J. (2002). Tecnologias do eu e educação. In T. T. da Silva (Org.), O sujeito da educação: estudos foucaultianos (pp.35-86). Petrópolis, RJ: Vozes.

Larrosa, J. (2014). Tremores: escritos sobre experiência (C. Antunes \& J. W. Geraldi, trads., 175 pp.). Belo Horizonte: Autêntica.

Louro, G. L. (2001). Pedagogias da sexualidade. In G. L. Louro (Org.), O corpo educado: pedagogias da sexualidade (2a ed., pp. 09-34). Belo Horizonte: Autêntica.

Marshall, J. D. (2008). Michel Foucault: pesquisa educacional como problematização. In M. A. Peters, \& T. Besley (Orgs.), Por que Foucault? Novas diretrizes para a pesquisa educacional (pp. 25-39). Porto Alegre: Artmed.

Meyer, D. E., \& Soares, R. F. (2005). Modos de ver e de se movimentar pelos “caminhos" da pesquisa pós-estruturalista em Educação: o que podemos aprender com - e a partir de - um filme. In M. V. Costa, \& M. I. E. Bujes (Orgs.), Caminhos investigativos III: riscos e possibilidades de pesquisar nas fronteiras (pp. 23-44). Rio de Janeiro: DP\&A.

Santos, L. H. S. dos. (2005). Sobre o etnógrafo-turista e seus modos de ver. In: M. V. Costa, \& M. I. E. Bujes (Orgs.), Caminhos investigativos III: riscos e possibilidades de pesquisar nas fronteiras (pp. 09-22). Rio de Janeiro: DP\&A.

Silva, K. da. (2011). Currículo, gênero e identidade na formação de professores (195 pp.). Dissertação de Mestrado em Educação, Programa de Pós-Graduação em Educação, Universidade Federal de Juiz de Fora, Juiz de Fora, MG.

Silva, T. T. (2006). O currículo como fetiche - a poética e a política do texto curricular (117 pp.). Belo Horizonte: Autêntica.

Submetido à avaliação em 29 de maio de 2015; aprovado para publicação em 28 de setembro de 2015. 
